http://dx.doi.org/10.30920/letras.90.132.5

\title{
José María Arguedas: poeta quechua de la transformación
}

José María Arguedas: quechua poet of transformation

\author{
Mauro Mamani Macedo \\ Universidad Nacional Mayor de San Marcos, Lima, Perú \\ Contacto:mmamanim@unmsm.edu.pe \\ https://orcid.org/0000-0002-0021-5488
}

Carlos Huamán López

Universidad Nacional Autónoma de México, Ciudad de México, México

Contacto: huamanlo@unam.mx

https://orcid.org/0000-0003-0998-4811

Yolanda Ruth Julca Estrada

Universidad Nacional Mayor de San Marcos, Lima, Perú

Contacto: yolanda.julca@unmsm.edu.pe

https://orcid.org/0000-0003-3922-9980

\begin{abstract}
Resumen
El propósito de este artículo es demostrar que, en Katatay, José María Arguedas representa el pachakutiy social a través de una convocatoria para cambiar el mundo y que esta convergencia para transformar no solo se da en el orden humano, sino que involucra toda la cosmovisión andina, donde hombres y dioses coinciden para pasar del temor a la decisión, y en esa ruta construir y celebrar la alegría volteando al mundo. Para el análisis, utilizaremos la categoría cultural de pachakutiy, que tiene una orientación cosmológico-social, ya que plantea la idea de la vuelta de mundo o del mundo al revés; es decir, un cambio radical. Esta idea la extendemos a la representación de los movimientos sociales que se suscitan en los pueblos con la intención de cambiar las condiciones deplorables de vida, que van desde juntarse para enfrentarse a naciones para obtener su soberanía, o enfrentarse a capas sociales dominantes que los oprimen. En tal sentido, utilizamos una metodología interdisciplinaria que convoca categorías de la literatura, la lingüística, la antropología y la historia con la finalidad de explorar con mayor amplitud la riqueza expresiva del poema quechua. Con ello demostraremos cómo el temblar (katatay) no solo es una convulsión del hombre o de una colectividad, sino que esta tembladera alcanza a los cielos, a todo el mundo, que participa interaccionando fuerzas para transformar, para que él mismo dé vuelta a las formas de vida establecidas.
\end{abstract}

Palabras claves: Arguedas; Pachakutiy; Katatay; Divinidades andinas 


\begin{abstract}
The purpose of this article is to demonstrate that in Katatay, José María Arguedas represents social pachakutiy through a call to change the world and that this convergence to transform not only occurs in the human order, but also involves the entire Andean cosmovision, where men and gods coincide to move from fear to decision, and on that route to build and celebrate joy by turning the world around. For the analysis, we will use the cultural category of pachakutiy, which has a cosmological-social orientation, since it raises the idea of the return of the world or the world in reverse; that is, a radical change. This idea extends to the representation of social movements that arise in the people with the intention of changing the deplorable conditions of life, ranging from joining together to face nations to obtain their sovereignty, or face dominant social strata that oppress them. In this sense, we use an interdisciplinary methodology that brings together categories of literature, linguistics, anthropology and history in order to explore more fully the expressive richness of the Quechua poem. With this we will demonstrate how trembling (katatay) is not only a convulsion of man or of a collective, but this trembling reaches the heavens, to the whole world, which participates by interacting forces to transform, so that he himself returns to the established ways of life.
\end{abstract}

Keywords: Arguedas; Pachakutiy; Katatay; Andean deities

Recibido: 16.10 .18

Aceptado: 22.09.19

\title{
Introducción
}

Katatay es título que da nombre a la compilación de siete poemas quechuas de Arguedas ${ }^{1}$. En ellos principalmente existe un programa transformador de situaciones socioculturales, característica presente también en su narrativa, donde se representa la búsqueda de las trasformaciones del estado de vida de los runakuna. Así lo advertimos en sus novelas Los ríos profundos (1958) o Todas las sangres (1964), donde los hombres sueñan y se cargan de coraje para enfrentar al gamonal y acabar con el sistema funesto que despojaba a los runakuna de su dignidad humana; pues, ante los gamonales, estos tenían el valor de un animal o de una cosa, por ello sus vidas pertenecían a la hacienda. Así, si un hacendado quería deshacerse de un "desobediente", lo castigaba o lo mataba. Por esa razón, sus personajes empiezan a soñar con un mundo más justo, diferente al que vivían y, en tal sentido, debían cambiarlo. Sin embargo, en las indagaciones y decisiones para transformar el mundo el hombre no está solo, sino que convoca a la comunidad y a las fuerzas de la naturaleza, porque en la cosmovisión andina 
todo está vivo, todo siente y tiene voluntad, todo es comunidad. No hay una separación dualista entre cultura y naturaleza, sino que esta también es parte de la interacción social. De esta forma, la naturaleza tiene ánimo y sensibilidad, por eso debe existir un respeto ético en su participación en normal convivencia; pero también es capaz de contribuir con su estabilidad o desestabilización, por ello los dioses pueden responder con lluvias devastadoras que inundan, con movimientos telúricos que desatan avalanchas y desparecen pueblos, entonces las fuerzas del mundo están vivas como el hombre y la sociedad.

Este registro y acento en su narrativa no es resultado de una simple exploración expresiva, tampoco está separado de su poesía quechua, sino que surge como una articulación nuclear con el referente andino, en cuya cosmovisión siente que todo está vivo. En Kawsay,

[...] lo viviente, aquello que alienta y unimisma al sujeto que percibe con todo lo percibido, y en razón de lo cual los elementos de la realidad quechua y los individuos que la pueblan participan de una misma condición: el alentar en el mundo, es sin embargo en Katatay (temblar), el breve, pero extraordinario poemario de Arguedas, donde esa fuerza lírica y esa articulación coparticipatoria se muestras con claridad indudable. (Larrú, 2003, p. 63)

La depuración expresiva de su estilo muestra su potencia lírica en estos poemas, porque el yo poético, o el hablante lírico, está lleno de mundo por las vías de la colectividad, se halla y pierde en el mundo en que vive; en este sentido, la palabra "mundo" se une en el poema dentro de un torbellino de vitalidad, todo lo cual hace que los poemas se constituyan en espacios o microuniversos donde confluyen fuerzas de distinto sentido, potencias negativas y conservadoras que trabajan para que nada cambie, para que todo permanezca dentro del sistema jerárquico y opresor, pero también otras potencias forjan los cambios en forma articulada y colectiva para hacer retornar la justicia y la dignidad humana a sus pueblos. En esta línea de reivindicaciones y transformaciones se ubican los poemas quechuas de Arguedas, en especial "Katatay".

En la poesía de Arguedas nadie vive como una individualidad, sino que se siente y expresa el espíritu comunitario extensivo, donde una piedra o un río es un ser vivo igual al hombre, porque son integrantes de una comunidad que considera Letras-Lima 90(132), 2019 
que todos viven y por ello merecen igual respeto y atención: vivos y muertos, plantas y piedras, animales y hombres, hombres y dioses, ríos y lagunas, cielos y tierras; todos en una ferviente vitalidad, porque están regidos por el kawsay.

En el poema en particular, esta vitalidad del mundo coparticipa en las trasformaciones de las situaciones de vida del hombre, que busca estados de ánimo positivos que se concretizan en el grito, el canto y la danza; pero, para cambiar las situaciones de vida concreta, debe realizar una afirmación de subjetividades, por ejemplo, despejar el temor y tomar decisiones como juntarse para cambiar, y esta decisión no solo alcanza a los hombres, sino a los dioses mismos. Por esta razón, la celebración de triunfo no solo se da en la tierra, sino también en los cielos mismos; ya que, si baja el resplandor del Sol desde el hanan pacha (mundo de arriba), también puede subir el brillo de la sangre desde el kay pacha (mundo de acá), así como también puede sentir el ukhu pacha (mundo de abajo), cuando la tierra absorbe la sangre y desciende por sus venas terrosas. Estos tres mundos se vuelven uno articulado y celebrante, tal como se observará en el poema.

En este contexto cultural y literario planteamos como hipótesis interpretativa que las tensiones vitalizadoras y transformadoras del hombre y la naturaleza se observan en el poema "Katatay". Estas se manifiestan a través de la relación íntima y tensa entre el hombre y el mundo, entre el hombre y los dioses, en la medida en que hay armonías celebrantes y aflicciones asumidas para lograr un mundo justo que permita pasar del miedo a la alegría colectiva.

Estas dinámicas culturales se incorporan en las tradiciones $\mathrm{y}$ manifestaciones culturales ancestrales del mundo andino, como la danza y el canto guerreros. Además, la propuesta temática del poema se instala en la secuencia radical de los movimientos de resistencia cultural, como el Taki Onqoy, la danza de la enfermedad. En dicho sentido, así como se danza y canta para curar un mundo enfermo, de la misma forma veremos en el poema que se juntan los hombres para danzar con la naturaleza, con su universo religioso, para trasformar las situaciones socioculturales en las que vive el runa. Además, vemos esta dinámica de resistencia y transformación, como el danzak o danzante de tijeras que con sus movimientos 
convoca a reunirse para dar vuelta al mundo, tal como lo representó el propio Arguedas en su cuento "La agonía de Rasu Niti". De esta manera, en el poema "Katatay", la danza es vertebral y simbólica porque busca accionar un mundo para lograr la alegría y la fiesta liberadora, tal como está en la escena final del poema.

\section{José María Arguedas: Huñunakuychik, juntarse en una sola gran sombra para transformar}

La idea del pachakutiy en la obra de José María Arguedas está asociada a los cambios sociales drásticos. Esto se puede percibir en el relato oral "El sueño del pongo"; en sus cuentos, como "Agua" y en sus novelas. Al respeto, Mercedes López-Baralt explica que:

El relato oral quechua que recoge y traduce Arguedas en 1965, El sueño del pongo, invierte el mundo real al premiar al sirviente o pongo y castigar al gamonal. En su poema "Tupac Amaru Kamaq taytanchisman (haylli taki) / A nuestro padre creador Túpac Amaru", de 1962, Arguedas propone el pachakuti de la subversiva andinización de la capital limeña que antes colonizara a la sierra. (2011, p. 106)

El pachakutiy se observa en el cuento "El sueño del pongo" cuando, a través del recuerdo del sueño, se trastocan las realidades por el surgimiento de una realidad inesperada en la que se invierten las posiciones. De esta forma, el gamonal lame el excremento del pongo y este se alimenta de miel, lo cual es una forma de voltear el mundo. En el segundo caso, en el poema a Túpac Amaru, se observa a través de los procesos de ocupación o reterritorialización; es decir, volver a tomar su lugar mediante la indianización de Lima, ciudad que simboliza el poder desde los tiempos de los españoles, ya que concentra el poder y este centro radicaliza su dominio sobre las provincias, entonces resulta simbólico tomar la cabeza del poder. En tal sentido, esta categoría andina se aplica de forma adecuada a estos cambios totales, donde se muestra una vuelta de mundo. En estos textos hay una clara muestra ideológica que da cuenta de trasformaciones sociales.

Los poemas donde se encuentra principalmente la representación de esta transformación son: "Katatay" y "Tupac Amaru Kamaq taytanchisman (haylli-taki)". En ellos, evidenciamos la búsqueda de la justicia, donde una 
colectividad emprende una lucha comunitaria. En el poema dedicado a Túpac Amaru, se reconoce la capacidad que se tiene de convocar su nombre. Es con esta fuerza con la que se subleva para ocupar Lima, la capital del Perú, lo cual es un llamado a retomar sus tierras. Desde este universo, busca cambiar el mundo, territorio de marginación y de injusticia que se socava desde el centro. En el caso del poema "Katatay", todo el universo de dioses, naturaleza y hombres se junta para cambiar el mundo; son convocados por el hijo del Sol (el Amaru, la serpiente dios), que con su palabra logra llamar a los hombres para que estos asistan al cambio, la fiesta transformadora que es acompañada por los dioses y la naturaleza, el complemento de los mundos.

El significado más elemental de Katatay es temblar, entendido como el movimiento rápido y frecuente que vive el hombre y el mundo. Esta agitación la observaremos en el poema en tres grandes momentos. Primero, cuando el enunciador (hombre), en tanto individualidad, tiembla de miedo porque no puede descifrar el mensaje que trae el cóndor; pero sí sabe que algo ha tocado la sensibilidad (sombra) de las mujeres. Segundo, cuando tiemblan o se agitan los cielos y la tierra: todo en el mundo vive un estado de crisis tremendo, como una especie de parto de un nuevo amanecer. En un tercer momento, se tiembla por la fuerza que se desencadena como consecuencia del triunfo e ingresan en la euforia de la danza guerrera y religiosa; además, ideológicamente entran en convulsión social y sienten el amanecer del mundo (paqary) que trae una nueva vida, sin nubes que eclipsen el corazón del pueblo, sino con un torrente de respuestas y fuerzas que agitan la alegría. En el poema podemos observar un cambio de la disforia a la euforia, del no-saber al saber, de la pena a la alegría, de la individualidad a la colectividad, de la sombra indescifrable a la sombra que ilumina.

En "Katatay" existe un hablante lírico que está ubicado en la posición de enunciador sacerdote-poeta-profeta que llama a la calma, pero también convoca a temblar, gritar y danzar con lo nuevo. Todo esto no es obra del hombre solitario y esforzado, sino de un ser integrado a la colectividad que se potencia cuando se junta (huñuy) con una sola gran sombra (puyu/llanthu), donde los dioses y la naturaleza coparticipan, juntos construyen y celebran la nueva vida sin nubes ni oscuridad. 
Ya dentro del poema, primero indagaremos en los significados discretos y extensionales de la palabra katatay, esto para observar las trasformaciones y secuencias significativas. El diccionario de Diego González Holguín registra que: "Ccatatatanmi quiruy, Cruxir los dientes, mostrarlos riñiendo, o regañar con otro. Quirucatatay. El cruxir de dientes de frio, o miedo como en el invierno, o de enojado el hombre, o el perro" (1989 [1952], p. 63). Aquí utiliza los dientes como un elemento que contribuye con la explicación del concepto de movimiento intenso. Así, los dientes crujen, se muestran, chocan, castañean. De esta forma, señalan tres estados: de frío, cuando se está en invierno; de miedo, cuando se experimenta temores; de rabia, cuando se está enojado; y para ello utiliza como imagen comparativa la rabia del perro, que traduce el furor animal del hombre: "regañar como el perro que riñe enojado". Los significados pertinentes para nuestro análisis son el movimiento por el miedo y la cólera. Otra de las palabras vinculadas a katatay es "katatatani. Arrastrar o lleuar arrastrando" (González Holguín, 1989 [1952], p. 138); del mismo modo lo registra en Arte y vocabulario en la lengua general del Perú [1586], en la edición de Cerrón-Palomino (2014, p. 62). Ello implica la existencia de una fuerza que remolca a alguna otra cosa sobre el suelo. Así, un hombre con su caballo puede arrastrar (katatatani) a un animal cuando no quiere avanzar; también puede arrastrar a un hombre cuando quiere declarar su poder y humillar al vencido, como ocurría con los castigos que imponían los hacendados a los "desobedientes", a quienes amarraban a los caballos y los arrastraban por los caminos, muchas veces ocasionándoles la muerte en una forma cruel de escarmiento.

Ampliando el alcance de esta última acepción de katatatani (arrastrar), figurativamente podemos sostener que una idea puede arrastrarnos por su fuerza o potencia convocante, nos puede conducir desde adentro o jalarnos desde afuera. De igual forma, la fuerza de una danza o de la música puede katatarnos, arrastrarnos con sus movimientos o melodías; pero recordemos que esos movimientos y ritmos no son simples impulsos, sino fuerzas orientadas, ya que tienen un fin: entrar en el combate, en la guerra, o celebrar las victorias.

En los diccionarios más recientes, "temblar" designa dos palabras: khatatatay y katatatay (Cerrón-Palomino, 1994, p. 48). Del mismo modo, 
podemos encontrar varias entradas en el diccionario de Jorge Lira y Mario Mejía Huamán: "Khatatáta. Tembladera, sacudimiento o temblequeteo frecuente. Trémulo. Khatatátay. Temblor, convulsión, tiritona, agitación, sacudimiento nervioso de frío o de temor, acción de temblar. Temblar, agitarse o sacudirse con movimiento seguido y frecuente" (2008, p. 205). Todo ello conduce básicamente a dos estados: el psicológico y el fisiológico. Un estado psicológico puede revelar una tembladera de miedo, pero también de furia; mientras que, en el sentido fisiológico, se puede temblar o convulsionar porque hay una fuerza interior que no cabe en el cuerpo, por lo que conmociona en un intento de liberarse de ella. Estos padecimientos y euforias, ya sean psicológicos o fisiológicos, se pueden colectivizar generando una multiplicación de fuerzas. Si relacionamos este fenómeno con una suma sinérgica, puede conducir a la configuración de una fuerza reproductiva, como los movimientos sociales que fermentan respuestas ante las injusticias, que terminan en los levantamientos por la reivindicación de las comunidades andinas, que han experimentado primero el temor, luego la rabia y finalmente la celebración, aunque muchas de ellas han culminado en masacre.

Los varios sentidos que observamos en la palabra katatay están representados en el poema en forma referenciada y figurada. Por ejemplo, en la idea de convulsión social, o cuando se señala los tiempos en que debe dejarse de temblar de miedo y pasar a mostrar los dientes por la furia que revela su enojo o su alegría que muestra su contento. Esta transformación tiene un sustrato ideológico, que puede convocar al levantamiento de un pueblo que siente esa convulsión; es decir, ser un pueblo que asume determinada fuerza o kamak que lo hace movilizarse cuando está unido, lo que despierta un valor que enlaza y subleva. Así, en el poema fueron convocados por una fuerza mayor, una fuerza mítica y divina que los alienta en sus movimientos cuando tienen que revelarse contra fuerzas desconocidas que infunden caos; de esta forma pasan de un tiempo de pururun pacha (tiempo oscuro) a uno de allin kawsay (a buen vivir). Todo ello crea un enlace cósmico, ideológico y social. En tal sentido, Julio Noriega entiende los poemas de Arguedas como poemas-manifiesto que "denuncia[n] la sistemática violencia de la que el mundo andino ha sido objeto a lo largo de su 
historia, justifica[n] y alienta[n] tanto a la revolución cósmica (katatay) como a la invasión pacífica del espacio urbano por los migrantes quechuas" (Noriega Bernuy, 2012, pp. 66-67). En el poema se representa una transformación cósmica que tiene resultados sociales inevitables.

Asumir el proyecto de la reivindicación implica recuperar la memoria, el pasado, la identidad, la fortaleza y sacudirse del miedo (katatay); pero también incluir lo que no se entiende para procesarlo y, una vez amansados los conceptos, usarlos en beneficio del proyecto. Es decir, asimilar ideologías externas, empalmarlas con ideologías nativas y, así trenzadas, configurar una gran fortaleza. Gonzalo Espino lo explica de esta forma:

Será también la memoria de ese tiempo en que todo era comunidad, como retórica del desagravio y la rabia contenida que apuesta a la transformación (pachacutiy), de los cambios que están sucediendo en el mundo y que afecta de diversas maneras a la vida indígena, a las que no se le tiene miedo, se las apropia, se las incluye, como se lee en el poema Katatay, Temblar [sic]. (Espino, 2012, p. 26)

Entendido así, katatay es temblar; kawsay, la vida que está en todo el mundo, la vibración; lo kamak, lo animado. En este canto hay un temblor de miedo; pero también hay ánimo, una vida ardida que intensifica la esperanza y la voluntad para involucrarse en un proyecto de liberación del miedo o del sacudimiento del mismo. Así, lo monstruoso nos puede generar una tembladera, como todo lo que desconocemos, porque no sabemos y por ello no podemos recibir o rechazar. Un acto sin sentido puede conducirnos a desastres, como ocurre con la enfermedad o la convulsión, que luego nos lleva al desvanecimiento y a la muerte. Este tipo de temor se experimenta en la primera parte del poema, cuando se vive en el temor: "Llaqtay puyus katatachkan / warmikunapallaki puyu sonqonwan tupaykuspa" ("Dicen que tiembla la sombra de mi pueblo; / está temblando porque ha tocado la triste sombra del corazón de las mujeres") (Arguedas, 1984, pp. 36-37). Aquí se observan varios conceptos, pero el concepto clave es puyu, que es lo que está temblando. Puyu significa, en quechua, "nube", todo aquello que impide la claridad, como las nubes que no permiten que lleguen los rayos del 
Sol; o un estado más extremo, como el "Puyuchacun pacha. Estar todo nublado por todas partes" (González Holguín, 1989 [1952], p. 299), como el estado tenso, previo al desencadenamiento de la tempestad. De esta manera, es el pueblo el que está nublado y no tiene claridad, lleno de temores que tiene el deber de despejar. Está así porque han tocado el temor que hay en el corazón de las mujeres. Allí están, allí se encuentra (tupay), en el cuerpo colectivo, porque se habla no de una mujer, sino de mujeres en plural (warmikuna); entonces es el miedo el que vive en el corazón de las mujeres y este temblor de miedo lo transmite a todo el pueblo. En la versión en español lo traducen como a puyu, como sombra, que en quechua es llanthuy. Este concepto es el que atravesará todo el poema: la oscuridad y la luz, la sombra y el brillo. En dicho sentido, la nube/sombra puede ser leída como un estado psicológico de sensibilidad que estaría ubicado en lo interior, incluso al interior del corazón, en el sunqu ruru, en la parte más sensible de este; es eso lo que está temblando, la sombra del corazón de las mujeres, que es la sombra del corazón del pueblo. Es en ese interior donde vive el temor, pero este no surge del interior, sino que viene del exterior, que es otra sombra que viene al encuentro, la que supuestamente trae el cóndor. Lo cierto es que este temor alcanza casi a la totalidad de los habitantes del pueblo, menos al tayta.

De tal forma, ante esta realidad, el enunciador expresa su temor a su destinatario, que es su padre (taytallay): "Manchakunim, taytallay", "Manchakunin, tatay" ("Tengo miedo, padre mío") (Arguedas, 1984, pp. 36-37). El temor ante esta ofuscación que no se aclara es intensa, y esto se observa con la repetición de los dos versos que, juntos, parecen formar un dístico semántico que se diferencia solo por la intensificación, ya que en el primero se expresa una mayor intensidad, mientras que en el segundo aparece la serenidad, como si el yo poético fuera cobrando seguridad para descifrar, pero es honesto en revelar el pavor que hay en su corazón, en su sombra-tembladera. Así, se pasa a reconocer a su destinatario como "padre mío", a mi padre, que no necesariamente es el padre biológico o humano de la colectividad, sino la divinidad andina (Tata Inti, Tata Intillay), el padre Sol, padre Sol mío - como se invoca en este himno-, un ser que tiene mayor conocimiento que él, quien no despeja el enigma mediante una 
respuesta directa, sino fiel a la configuración colectivista andina, construye el conocimiento en forma social. Por ello, no hay una respuesta que cierra, sino un acercamiento para ir develando juntos el enigma.

No enuncia que vienen los cóndores, sino su sombra; porque no es la llegada del animal — sino lo que proyecta-, el mensaje que está oscuro, en sombra. No obstante, pide no temblar: "AAma katataychu!" ("No tiembles") (Arguedas, 1984, pp. 36-37), porque observa la llegada de un cóndor con una sustancia o fuerza aún indefinida: "-Imapaqmi hamun chay sombra/aukikunapa sutipinchu / icha Jesus yawarninpa kamachisqanchu” ("- ¿A qué viene la sombra? / ¿Viene en nombre de las montañas sagradas / o a nombre de la sangre de Jesús?" (Arguedas, 1984, pp. 36-37). Aún no conoce a qué viene ni de quién es esa sombra, de quién es el mensaje, lo que ratifica el carácter mensajero del cóndor. La sombra se cifra como una voluntad, como un mandato de los dioses.

Hasta aquí podemos observar que los sistemas de codificación son básicamente de colores. Aquí no hay un cóndor que habla, pero sí que transmite mensajes y estos están señalados por lo oscuro. Así se estructuran las divinidades. El kuntur, que es como un mensajero, un trasportador de la energía de dos posibles poderosos, tal como se proyectan desde el kay pacha, los auki o Jesús. Los aukikuna son las montañas sagradas y Jesús que, si bien pertenece a la religiosidad occidental, en el universo andino ya tiene la categoría de apu, de auki; es decir, Jesús es un apu. Tal como lo ha recordado Martín Lienhard, siguiendo a Núñez del Prado: "La presencia de 'Jesucristo' en un canto quechua no debe sorprender: en el panteón surandino, Cristo existe como una divinidad de rango intermedio $(a p u)$, especializada en las quejas por injusticias sufridas" (Lienhard, 1998, p. 36). En efecto, los apus son divinidades intermedias y por encima de ellos está, por ejemplo, el Tata Inti y la Mama Killa; y debajo de ellas está el apu Jesucristo. En tal sentido, hay una mayor proximidad con la comunidad que protege. Los hombres de la tierra consideran que viene su sombra, su presencia viene a nombre de ellos; pero, como veremos, esta intuición no es cierta, ya que mediante la construcción social del conocimiento irá descubriendo el verdadero mensaje. 
En efecto, esta técnica de preguntas y respuestas establece el carácter dialógico del poema, tal como precisa Julio Noriega:

[...] el haylli (himno) es todo un género que se constituye sobre la base de un discurso dialógico. En este género hablan los dioses, se comunican con el sujeto poético a través de diálogos ritualizados. Este sujeto, como si estuviera realizando un acto ritual, invoca a sus dioses le da cuenta de la realidad. (Noriega Bernuy 2011, p. 129)

Noriega reconoce así la dualidad andina en el diálogo a través de las preguntas y respuestas entre el enunciador y el interlocutor del poema "Katatay". Ello empalma con la cosmovisión andina que se rige por principios como el de la complementariedad; por ejemplo, el yanantin donde la interrogante y la respuesta van juntos en el camino del desciframiento del enigma, que en esta parte del poema consiste en saber a qué divinidad pertenece el mensaje y cuál es su significado.

Antes de avanzar en el análisis, es necesario explicar el significado del cóndor para señalar su lugar dentro de la religiosidad andina. En la cosmovisión andina, las divinidades intermedias como los apus tienen como mensajero al cóndor, que también posee poderes divinos, pues comunica el hanan pacha (mundo de arriba) con el kay pacha (mundo de acá). Por ello, el cóndor es considerado hijo del apu. Su majestuoso vuelo cuida y gobierna a esta deidad y, para acceder al $a p u$, se debe hacer un pago, un ritual andino que permite el acceso respetuoso a sus dominios. Cuando uno sube por allí, surge el cóndor en su vuelo intenso y dominante. Para el contexto del Altiplano, explican Denise Arnold y Juan de Dios Yapita que en esta región se le considera al cóndor como un agente regenerador y destructor (Arnold \& De Dios Yapita, 1992, pp. 129-131). Primero, porque es capaz de transformar una cantidad de piedras en una cosecha de papas y puede agarrarlas y "hacerlas encender"; es decir, hacerlas crecer en abundancia, como la difusión de la luz en el suelo. Segundo, porque es capaz de agarrarse los alimentos y agotarlos, esto porque mantiene la dualidad de protección y sanción. También el cóndor es simbolizado como un nido y fuego de la casa, como centro irradiador. Además, el cóndor puede ser una metáfora de aquellas personas que tienen que ver con los procesos de producción y agotamiento de los productos; es decir, encarna a los causantes de la abundancia y la carestía. 
También recordemos que, en Dioses y hombres de Huarochirí, el cóndor es uno de los animales bendecidos por el dios Cuniraya cuando desesperadamente este busca a Kavillaca. Así, Cuniraya Viracocha se encuentra con el cóndor y con él establece un diálogo esperanzador, por lo que recibe augurios favorables:

Entonces, este Cuniraya Viracocha: "Mi hermana ha de verme, ha de aparecer" diciendo, llamándola y clamando, se alejó del sitio [Anchicocha]. Y se encontró con un cóndor antiguo. Le preguntó al cóndor: "Hermano, ¿dónde te encontraste con ella, con esa mujer?", "Muy cerca de aquí - le contestó el cóndor- has de encontrarla". Y Cuniraya le dijo: "Tendrás larga vida. Cuando mueran los animales salvajes, ya sea huanaco o vicuña, o cualquier otro animal, tú comerás de su carne. Y si alguien te matara, ese, quien sea, también morirá". Así le dijo. (Arguedas, 2007, p. 17)

Entonces, el cóndor es bendecido por una divinidad mayor, alarga su vida y designa la forma de subsistencia. En tal sentido, el cóndor es una divinidad dual y su presencia puede anunciar el bien o puede traer el mal. De allí la duda que tienen los personajes del poema, porque él trae una sombra: "Kunturpa sombranmi hamuykuchkan” (“¡La sombra de los cóndores se acerca!”) (Arguedas, 1984, pp. 36-37). La duda (icha: "tal vez") viene a nombre de las montañas o de la sangre de Jesús ("Icha Jesus Yawarninpa kamachisqanchu”); pero la llegada del cóndor no es gratuita, sino que trae un mensaje que ellos esperan saber para aclarar la nube temblorosa de su corazón. Aquí el verbo clave es "kamachiy", que significa “orden", "mandado", "ley”, "indicar”, “disponer”, que da cuenta de las órdenes jerárquicas impartidas por los apus o por otros dioses mayores, porque no es una simple orden de un poderoso, sino que es el mandato divino; por ello, el peso religioso de la orden la vuelve significativa y solemne. Para el caso de Jesús, se menciona que no viene a nombre de él, sino a nombre de su sangre, aquella derramada por Cristo que se sacrifica por los hombres, que da su vida por ellos; por esta razón, se va hacia él con invocaciones, plegarias, quejas, para que pueda ayudar a mitigarla. De esta manera, la sangre de Cristo es significativa por haber sufrido, por escuchar las quejas de los hombres, pero ya converso e instalado en el panteón andino con jerarquía de $a p u$. Esta indefinición de saber si pertenece a él o no hace sentir miedo al enunciador (Manchakunim, taytallay). 
En su indagación, encuentra que el cóndor no viene ni a nombre de los apus ni a nombre de la sangre de Cristo ("Manan yawarchu / manan auki wamanichu"), sino que viene de una divinidad más elevada: el Tata Inti y que no es una sombra la que trae, sino una luz, un brillo: "Intipa kanchariyninmi kuntur rapranpi hamuchkan" ("Es el resplandor del Sol que llega en las plumas de los cóndores") (Arguedas, 1984, pp. 36-37). Sin embargo tampoco es algo esperanzador, que trae alegría inmediata, sino que con su resplandor trae el anuncio de una crisis mayor y al mismo tiempo una convocatoria. De esta forma, opone oscuridad (tiempo malo) a claridad (tiempo bueno); pero, para saltar de un tiempo a otro, se tiene que enfrentar y superar la crisis. No hay un paso gratuito y mecánico, sino que es un resultado de un esfuerzo colectivo; además, se debe sentir la crisis.

Así, aparece el Tata Inti con su poder devastador ejecutando esta crisis extrema: "Intiqa kañanmi, uywakunata, kausayta", que en la versión en español expresa: "El Sol quema; quema al ganado, quema las sementeras" (Arguedas, 1984, pp. 36-37); este verso parece representar todo un escenario, el chawpi, el que señala, el tickray, la vuelta el pachakutiy. Señala un estado de tremenda desolación. Un pachakutiy se representa mediante la acción del agua o del fuego; de esta forma, el agua puede inundar y desaparecer un pueblo y cerrar un periodo, para que vuelva a surgir otro tiempo. Igual efecto puede tener el fuego, como las erupciones volcánicas o el fuego del campo cuando se quema la hierba para que vuelva brotar. En este caso, es el fuego del Sol el que destruye el kawsay, la vida, que presenta una destrucción vasta de aquel dios que debe proteger y que ahora destruye los sembríos y los animales. Este es el comportamiento de las divinidades andinas, ya que muestran su dualidad; por ello, pueden operar cambios drásticos - por ejemplo, el Inti aparece como un dios castigador-. Es como si esta crisis permitiera ver más claramente la situación y luego, con un trabajo colectivo, liberarse de ella. Recordemos que los pueblos de diferentes culturas, cuando entraban en crisis, muchos de ellos acababan matándose, enterrándose, destruyéndose, para que aparezca una nueva vida, un nuevo despertar. Ello lo podemos ver en este verso en forma más clara en su versión quechua, porque el Inti no solo quema los animales, sino algo más extremo: quema la vida (kawsay), 
como si el dios destrozara esta vida para que brote otra, porque estaba enferma, para lo cual se necesita una "cura cósmica" y una "cura histórica", como plantea Ranulfo Cavero al conectar el taqki onqoy con el pachakutiy, relación que contribuye con la explicación de este verso chawpi:

La inminencia de la catástrofe cósmica e histórica (que el mito de Pachacuti da cuenta), ahora acelerada por la conquista española y traducida en el Taki Onqoy, fue metaforizada por los nativos en términos de una "enfermedad total" que amenazó diezmar a la población entera, donde las mismas divinidades estaban dolientes y debilitadas, la propia sociedad y el tiempo estaban enfermos. (Melgar y Cavero, 2007, p. 59)

Es el tiempo de crisis donde los elementos se trastocan, donde los dioses poderosos también castigan a los descarriados, por lo que se debe respetar y revitalizar a las wakas (las cuales se podían expresar por medio de sacerdotes); además, "el Taki Onqoy no buscaba la recuperación del pasado, más al contrario anunció su transformación y adaptación al proceso histórico nuevo que buscó enfrentar" (Melgar y Cavero, 2007, p. 60). En tal sentido, este es un momento en que el poema se conecta con el movimiento radical de respuesta antihispánica: taki unquy. Así, se plantea que: "La lectura de Katatay reactualiza la voluntad de Taky Onkoy, pero dotando a la figura religiosa de un aspecto político, reafirmando la confianza en la capacidad de acción del ser humano" (Huamán, 1988, p. 107).

En el poema, el dios Inti destruye y quema la vida para hacerla brotar, así como en el campo se quema la maleza, el pasto viejo, que no alimenta ni crece, para que debajo del manto de ceniza pueda surgir una hierba más fuerte, nutrida con las cenizas mismas del pasto viejo. Así, el Tata Inti quema la vida vieja para renovarla; es la fuerza de la luz (kanchay) la que engendra y alumbra una nueva vida. Por esta razón, lo que trae el cóndor no es el Sol, sino su brillo: "Manam Intichu, sonqonpa kusiy, qapaq kanchariynillanmi / kundurpa sombra ñawinpi hamuchkan" ("No es el Sol, es el corazón del Sol, su resplandor / su poderoso, su alegre resplandor / que vine en la sombra de los ojos de los cóndores") (Arguedas, 1984, pp. 36-37). De la misma manera como no habla de Cristo o Jesús como totalidad, sino de su sangre, ahora habla no del Sol, del Inti, sino de su luz, 
del resplandor de su corazón. Es del centro de donde brota la luz poderosa que iluminará a los hombres, pero que también puede quemar para que surja otra vida o se produzca una renovación, un cambio drástico. Allí podemos ver que existen dos tipos de brillo que trae el cóndor como mensaje: como sustancia que emite el propio Sol e ilumina, y como brillo que quema y destruye, pero que renueva. El primero está en el saber, en lo cognoscitivo; el segundo reside en el hacer, en lo pragmático. Ambos elementos se encuentran (tinkuy) para construir una nueva vida, como se verá al final del poema, donde el mundo danza en alegría.

En efecto, luego del verso chawpi, se aclara la sombra en el brillo. Así, en el poema brota otra vida impulsada por la divinidad de la serpiente, machaqway, que es hijo del Sol (Intip Churin) y aparecen convocando y renovando el sentir y el pensamiento de los hombres. En efecto, la serpiente, el amaru, el Katari, es una divinidad que está asociada al pensamiento, un ser sabio. El amaru es una de las deidades que tiene mayor presencia en el mundo andino y se le atribuye diversas vinculaciones, como la generadora de las lluvias y su desplazamiento contorsionado, y en avance se le asocia con los movimientos sociales. Diego González Holguín registra: “Amaro. Dragón, Serpiente” (1989 [1952], p. 24). Explica Ayala Leonardi que:

En la región Anti se adoraba al Amaru por su mansedumbre y enormes proporciones. [...] Dicen que antes los amarus eran de gran fiereza, en cierta oportunidad, uno de estos animales mató a la hermosa hija de una hechicera; esta en venganza, encantó al animal haciéndolo inofensivo. (Ayala Leonardi, 2002, p. 21)

La representación de los movimientos del amaru se ve en varios soportes; por ejemplo, en los tejidos, donde el zigzag simboliza el movimiento del agua, de la vida y la serpiente, como dice Margir Gutmann:

Este zigzag está muy difundido en la cultura andina y se llama q'enqo. A menudo se encuentra con diseños en los tejidos. Simboliza la continuidad de la vida y las corrientes de agua. El q'enqo es también símbolo de la serpiente. (Gutmann, 1993, p. 248)

También se asocia a movimientos sociales, como explica Juan Rivera: 
El amaru es una misteriosa entidad ectónica, conocida solo en los Andes del sur del Perú. Suele ser representada con la figura de una enorme serpiente y se cree que es la causa de los grandes desplazamientos de lodo y otros accidentes. El concepto de amaru ha adquirido popularidad a partir de personajes históricos que se llamaron a sí mismos con este título: uno de los últimos Incas (Túpac Amaru I), un cacique que organizó una revuelta contra el poder español durante el Virreinato (Túpac Amaru II). (Rivera Andía, 2006, p. 151)

La sangre del amaru tiene poderes curativos y de esta forma puede limpiar nuestra sangre: "Los campesinos beben la sangre de las serpientes no venenosas inmediatamente después de decapitarlas, dicen que es un presente de sus dioses y creen que la sangre de la serpiente purifica el torrente sanguíneo humano" (Avendaño, 1988, p. 388). Esta propiedad de ser una sustancia regenerativa se observa en el poema como una imprecación que formula el enunciador a los hombres para que celebren el amanecer, pero también el significado que se vincula con los movimientos sociales de reivindicación.

Así, advertimos que, luego de la aparición de la serpiente en el poema, el enunciador cambia completamente de tono y asume la fuerza de la serpiente que camina hambrienta en los bosques: "Orqokunapis, may sacha sachakunapis, / yarqasqa machaqway, Intip churin", que en la versión español aclara su accionar: "Dicen que en los cerros lejanos / que en los bosques sin fin, / una hambrienta serpiente, / serpiente diosa, hija del Sol, dorada, / está buscando hombres" (Arguedas, 1984, pp. 36-37). Ahora estamos frente a un enunciador convocante; de esta manera, la serpiente convoca hombres para juntarse y formar una sola fuerza o sombra, como si ella estuviera encargada de hacer cumplir la voluntad de su padre Sol, porque tiene la fuerza y la iluminación que provienen de él, tiene su sangre y sustancia.

Precisamente, lanza una voz convocante para que los hombres puedan levantarse: ";Sayay, sayariy! Chay mana chanin kunturpa ñawinta / chaskiy; katatay paywan” (“iLevántate, ponte de pie; recibe ese ojo sin límites! / Tiembla con su luz") (Arguedas, 1984, pp. 36-37). Observemos que, si antes el enunciador pedía no temblar (ama katataychu), ahora lanza un llamado intenso a hacerlo, 
porque la significación se invierte: si antes era temblar por el miedo, ahora es temblar para el triunfo, temblar con el gran resplandor para celebrar la lucha, para lo cual tienen que estar juntos, unidos, ya que solo de esa forma se puede pasar de una tembladera de miedo a una tembladera de felicidad: “iHuñunakuychik, llaqtay runa, / kanchiriywan katataychik!" ("Formen una sola sombra, hombres, hombres de mi pueblo") (Arguedas, 1984, pp. 36-37). Ahora se tiene que danzar con la luz que viene de la divinidad andina, del corazón del Sol, enviada por medio del cóndor; por ello, les pide que la reciban, que se envuelvan en esa luz y vivan en ella, pero también deben beber la sangre de la serpiente dios: "Amaru yawarta upyaychik" ("Beban la sangre áurea de la serpiente de dios") (Arguedas, 1984, pp. 38-39). Así como los campesinos que matan las serpientes que no son venenosas para beber su sangre y purificar la suya, de la misma forma pide el yo poético que los hombres beban esta sangre para que ingrese el valor, para que los purifique del miedo, porque en ella está la fuerza de la serpiente, que no es una sangre roja o de otro color, sino es una sangre de oro (chay qori yawar). Esta sangre ardiente no solo debe ingresar a los hombres para levantarlos, para mantenerlos de pie y juntos, sino que llega hasta el ojo del cóndor. Recordemos que el poderoso resplandor que sale del corazón del Sol viene en sus ojos específicamente, en la sombra del ojo del cóndor - y es hasta allí donde se eleva y llega la sangre del amaru.

Esta participación colectiva de la euforia convoca la presencia del mito y el rito, en el sentido en que lo explica Limón Olivera:

[...] en el rito se revelan y reviven los mitos a los que aluden y esto únicamente se da en una atmósfera de festividad religiosa en que todo el pueblo participa. Se puede decir que el mito es el aspecto teórico de la religión pues se refiere a la explicación ilusoria del mundo. El rito, por otra parte, es su forma práctica ya que tiene como función transformar al mundo de manera imaginaria. Por medio del mito se actúa mágicamente sobre la realidad. (1990, p. 26)

Precisamente, esto es lo que se observa en el poema: fiesta colectiva para la transformación cósmica del mundo, en la cual se sigue un ritual festivo que involucra al universo vivo. 
Esta serpiente es el amaru que convoca a los hombres para juntarse, vencer la adversidad y celebrar; no para tragarlos, sino para darles su sangre luminosa, áurea, para que formen una sola gran sombra. Este mecanismo de convocatoria es como si estuvieran juntando pedazos del pueblo que fue desmembrado, como el Inkarrí que ahora busca unificarse; además, recordemos que el amaru es una divinidad del ukhu pacha. Hay dos elementos que ayudan a esta hipótesis interpretativa. El amaru está asociado a los movimientos de reivindicación, como el caso de Túpac Amaru y el retorno mesiánico del Inkarrí, quien fue despedazado y que ahora se junta para completarse. De igual forma, la serpiente — hambrienta de justicia — busca a los hombres en cerros lejanos — que serían las estancias-, a los comuneros, a los hombres del ande y en los bosques (recuérdese los movimientos del Gran Pajonal, las rebeliones indígenas, como la de Juan Santos Atahualpa) (cfr. Lienhard, 2008, pp. 51-70), para formar todos juntos un pueblo. Otro elemento básico es la unión entre el movimiento de la naturaleza, el baile, el temblor de la tierra, el temblor del hombre, el temblor del pueblo, todo lo cual connota vida que da cuenta de que están en kawsay, están en vida.

Recordemos que la sangre es uno de los elementos fundamentales en el poema. Así, tenemos la sangre de Jesús y la sangre de la serpiente. En el poema, la sangre de Jesús queda postergada; pero se le reconoce su posibilidad de hacer vibrar, de generar movimientos sociales. En el poema, esta sangre no es la que provoca el cambio, sino la sangre de la serpiente, ya que la sangre del amaru es la que tiene mayor poder y la que están llamados a beber los hombres para fortalecerse. Además, a Jesús lo ubican jerárquicamente al mismo nivel que el dios montaña. A ambos, Jesús y los apus, se les reconoce en el poema su capacidad de hacer temblar; en este caso no son los impulsadores. Al contrario de la serpiente, que tiene intensidad para convocar a los hombres y lanzar su sangre a los cielos en señal de victoria; de esta forma, se junta con la sangre de su padre el Sol, que llegará a iluminar y transformar. En tal sentido, la sangre del Sol sería la áurea luz, como es la sangre de la serpiente (ambas de oro); por ello, se declara Intip Churin (hijo del Sol), entonces habría una conexión por la sustancia, que suma características simbólicas y referenciales como el color, el brillo, lo ardiente, que 
luego se reúnen en el ojo del cóndor, pero sobre todo hay una conexión con su proyecto de sembrar la luz y la alegría.

Justamente, en el ojo del cóndor se produce un tinkuy de sangres: una que viene del hanan pacha enviada por el Sol y la otra que proviene de la tierra, del kay pacha, enviada por el hijo, el amaru. Las dos tienen la misma naturaleza, ya que poseen el color del oro, su brillo; este metal precioso alude a la divinidad alta de los Andes, que es el Sol. Estas dos fuerzas hacen emocionar a los cielos y los hacen bailar: "Cieluta huntanmi, tusuchinmi" ("Carga los cielos, los hace danzar") (Arguedas, 1984, pp. 38-39). Qué cosa es el cargarse los cielos, sino llenarse de nubes negras que están propensas a desatar la tempestad; eso es cargar los cielos, pero ya no con un sentido de desastre, muerte o castigo, sino de triunfo, de ahí el baile, porque viene la fertilidad con la humedad y luego la abundancia. Las nubes cargadas representan la felicidad; de esta manera, el puyu de los primeros versos, que simbolizaba la sensibilidad turbada del pueblo o de las mujeres, ahora al final del poema sería yana puyu, las nubes negras que tiemblan de felicidad, que combaten el chaki, el kañay, lo seco y el fuego que representan las crisis. Ahora con la lluvia aparecerá el tiempo nuevo, el verdor de los campos y la fiesta en los corazones de hombres y del pueblo.

Esta es la sangre que engendra. Aquí se desarrolla una figura sumamente compleja: la tierra que fecunda a los seres del hanan. Es común ver cómo los dioses engendran la vida de arriba hacia abajo; por ejemplo, el illampu (el rayo) que conecta el hanan con el hurin, el hanan pacha con el kay pacha, como si bajara para fecundar. Otro caso es la lluvia, que llega, humedece la tierra, abre la semilla, engendra y brota la vida. La sangre, como sustancia engendradora, va de la tierra a los cielos, del kay pacha al hanan pacha. Llega al ojo de los cóndores, que son los seres intermediarios; pues en sus alas y en la sombra de sus ojos llega la luz que ilumina al hombre. Ahora esta sangre engendradora, hirviente, sangre en movimiento, llega a los ojos de los cóndores. Eso es lo que hace desatar un movimiento en el cielo que desencadena la creación y la vida. Así como hay un movimiento en la tierra de tal dimensión que llega a replicar en el cielo, donde se encuentra el creador, el ser que es capaz de parir y crear, como Pachakamac o 
Wiraqucha, también de la tierra surge un rayo de sangre hirviente, que asciende al cielo, en un tinkuy sanguíneo; y ya que la sustancia que contiene es de brillo, es como si, dentro del sentir andino de la reciprocidad, del gran ayni, vuelve la sangre a su origen, mostrando una circularidad increíblemente regeneradora.

Con ello todo está en katatay, todo está en tusuy, en temblar el cuerpo en el sentido de danzar. Así danzan los pueblos, los hombres, los dioses, los cielos; todo el mundo (tiqsi-muyu) está en movimiento (muyuy), hasta las nubes ( $p u y u)$, que antes hacían temblar porque no se miraba claro y que ahora son las que cargan el cielo y lo hacen danzar. Estas danzas rituales recuerdan los tiempos en que los runas salían a espantar la enfermedad, porque con danzas y cantos también se cura. También recuerdan los rituales para espantar las heladas o la sequía: "Se organizaban procesiones en que los participantes armados tocaban tambores y lazaban gritos de guerra para espantar la sequía y la helada que amenazaban más al maíz que a los demás cultivos. Sacrificio de llamas, ayuno, ofrendas de agradecimiento y demanda de favores futuros eran parte de la cosecha" (Murra, 2014, p. 150). Danzas que guerrean contra la adversidad.

La idea de la conmoción social o del levantamiento en la tradición poética está representada en sayariy, hatariy (pararse, estar de pie, levantarse), vinculado a un despertar (rikchariy), a un grito (qapariy), a un parir o nacer (paqary), que es llamar a viva voz, a una nueva vida; tal como se convoca en el poema: “Sayay, isayariy!” (“Levántate, iponte de pie!”). Pararse para caminar y juntarse (huñuy), reunirse para "qapariyta kachaykuy" (empezar a gritar) y danzar (tusuy), todo ello para llegar a un amanecer tal como cierra un poema: "Paqariy, taytay, vida, runachallay runa, / ancha kuyana" ("Crea tú, padre mío, vida; / hombre, semejante, mío, querido") (Arguedas, 1984, pp. 38-39). Esta idea del himno y del grito fue advertida por Alberto Escobar como una característica de los poemas de Arguedas:

Es así como estos poemas pueden ser tenidos por himnos que en su oración decantan la fuerza del testimonio y el grito contra el tiempo: la voz rueda de sus páginas se instala en una curva que avanza desde el periodo legendario y se aventura en el porvenir, con manifiesta voluntad de historia. (Arguedas, 1972, p. 11; resaltado nuestro) 
En efecto, es un himno, como el propio Arguedas llamó a este poema; pero también es un grito de liberación frente a los temores que viven en su corazón por la luz que trae el cóndor y por la sangre de la serpiente dios. Así, el poema se ubica dentro del contexto cósmico-social y que busca un kuti, una vuelta o pachakutiy (una vuelta de mundo) donde la fuerza mítica es notoria.

Esta es la invocación que formula el hablante lírico al levantamiento, que tiene distintas dimensiones semánticas. Una primera es la mecánica y simbólica: simplemente dejar de vivir de rodillas, dejar el sufrimiento y la opresión, pasar de este estado a otro donde el hombre se pone de pie y enfrenta los problemas; pues cuando está de rodillas, no tiene voz, no puede gritar, solo tiene silencio y sometimiento. Por ello, cuando se pone de pie, recién puede gritar. Aquí la imagen del árbol (sacha) es fundamental, ya que está de pie y tiene movimiento. Esta imagen del árbol es la que debe estar en el hombre: pide moverse como los grandes árboles, moverse junto a ellos y empezar a gritar, porque el grito es una liberación, retomar su palabra reprimida como su ser. Este es el segundo significado, que es más social: el levantamiento, que es el movimiento inmediato y secuencial después de ponerse de pie. El levantamiento de las comunidades en el Perú tiene una larga historia, y estos han acabado muchas veces en masacres, pero las otras acabaron en estallante alegría.

En el poema, hay dos seres que alimentan la vida de los hombres: la serpiente y el Sol, ambos con sustancias poderosas. El Sol tiene su luz que nos envía de la parte más pura, del centro de su corazón. El mensajero que trae su luz de lo alto, en sus alas, es el cóndor. Por su parte, la serpiente tiene como sustancia poderosa su sangre hirviente. Estas dos sustancias (luz y sangre) están marcadas por la intensidad y permiten orientar y nutrir el movimiento de los hombres andinos, porque el poema está hablando del pueblo indio.

En sus desplazamientos se encuentran sonidos en movimiento $(y l l u)$ y sonidos luz. Hay luz y color en los desplazamientos. La sangre en su paz, su sonido es armonioso. Este sonido armonioso se rompe por el movimiento convulso del baile cuando la sangre se enfurece, hierve o grita. En el mundo andino, hay 
movimientos de luces y colores y estos tienen un sonido. El arco iris, que es la refracción de los colores; la illa, que es trueno y sonido; el rayo, que es el trazo; y el relámpago, que es el haz de luz, una candela voladora. Curiosamente, el color áureo de esta candela es el que tiene ahora la serpiente: su sangre es áurea. Hay pues movimiento, sonido, color, que por momentos se vuelve turbulento. Cuando el hombre se pone de pie, todo está iluminado, la sombra misma es una luz enviada desde el corazón de la divinidad. Por esta razón, la serpiente se constituye en un componente cultural simbólico puesto que activa un discurso mítico que fortalece los lazos de una comunidad.

La sangre, tanto en el mundo andino como en otras culturas, tiene diversos símbolos y es un elemento recurrente en la obra de Arguedas. Por ejemplo, en el poema dedicado a Guayasamín, encontramos a "yawar qapariq" (sangre que grita) como personificación de un ser que es capaz de protestar. En su novela Los ríos profundos está el enunciado "sangre hirviente"; en este caso, la sangre está vinculada a Jesús, que es la sangre que queda relegada y que puede tener colores (como en el poema): puede haber una sangre roja, pero también una sangre áurea, ya que el color tiene un significado en el mundo andino. Así, el rojo en el Ande es un color asociado a la madre tierra, a la fertilidad; por ejemplo, cuando se quería asegurar la cosecha de las papas, se sacrificaba una llama y, con su sangre, eran bañadas las semillas escogidas (Murra, 2014, p. 148); o cuando la tierra tiene este color: "Se cree que la tierra roja y fangosa, como la sangre de las mujeres agarra a la semilla-guagua y la fertiliza" (Arnold \& De Dios Yapita, 1992, p. 145). Las mismas mantas, las istallas, cuanto más rojas, más agradables a la pachamama, a la madre tierra. Además, el rojo también está vinculado a la guerra, pero no solo en el sentido bélico, sino como la "semilla que guerrea", que hace perdurable la vida andina con toda su identidad.

Sin embargo, en el poema hay otro color de la sangre: qory yawar (sangre de oro), cuyo color próximo es el amarillo ( $q^{\prime} i l l u$ ), que en el mundo andino está vinculado con los dioses, a los awichus, a los abuelos y mantienen una orientación masculina, pues se le relaciona con la luz del Sol (color de oro, amarillo). Como 
el caso de las plantas (como el maíz o el trigo), de allí que simbolice el poder: beber la sangre de oro de la serpiente, en tanto hija del Sol, da cuenta de que están unidos por el vínculo sanguíneo y simbólico, pues son del mismo color, vienen de la matriz fluyente del Sol, lo que implica recibir el kamak, la fuerza raigal de sus dioses. En tal sentido, beber su sangre es beber sus principios, su cultura, su mundo y seguir siendo alimentados por la fuerza divina, como en el Taki Onqoy, donde la fuerza de los dioses ingresaba al cuerpo de los hombres para desde allí operar el retorno del tiempo antiguo y bueno.

Uno de los momentos fundamentales del poema es el tusuy (danzar), que se junta con el katatay (temblar) y kuyuy (mover), que de alguna manera se unifican en la danza, porque la voz poética pide temblar con el gran resplandor, moverse con los grandes árboles de la selva y danzar con los cielos cargados. Esta idea del movimiento y la danza está en la inspiración del poema, confiesa Arguedas:

Ñoqa, José María Arguedas, Puquio Chaupi aylluruna, kay hayllitakita qellqarqani, Ishua llaqta wawqey kunata taksa wasichanpi Virgen Cocharcas visperanta tusuyta qawaykuspa. Ñuqapas tusuchaykurqani, takichaykur qanitaq, Ishua sumaq wawqeykunawan; kimsa punchao Sitimbre killapi, Pueblo Libripi, kay hatun llaqta Limapi.

[Escribí este himno luego de haber visto bailar a mis hermanos, hijos del pueblo de Ishua residentes en Lima. Bailaron en una pequeña habitación de adobes y techo de totora, en el canchón de la av. Sucre 1188, Pueblo Libre, el 3 de setiembre de 1965.] (Arguedas, 1984, pp. 38-39)

En la relación entre texto y contexto podemos apreciar el movimiento de la danza que hace temblar a la tierra, que convoca y hace unir, donde los espectadores existen; así Arguedas cuenta en una nota que también danzó y cantó con los hermanos de Ishua en esa pequeña casita (taksa wasicha). Luego de ver y vivir esta unión, escribió este poema. De esta forma, la danza transformadora que viene del zapateo, que hace temblar a la tierra, la conduce al poema.

\section{Tukuy (conclusión)}

El poema "Katatay" esta asistido por una dualidad: lo oscuro, como el puyu, 
la sombra, lo negro de sus ojos, y ello tiene diversas trasformaciones, porque una sombra puede significar el temor cuando no se sabe o el soporte de la luz o el momento de más alta fortaleza, como cuando se juntan todos los hombres en una sola gran sombra; el otro par complementario es lo resplandeciente, lo que implica que hay momentos de oscuridad, pero también existen momentos luminosos donde se recomponen los órdenes destruidos en las crisis. Es más, en lo negro es donde vive el resplandor, tal como se observa en el poema cuando la gran luz del Sol viene en la sombra de los cóndores, en lo negro de sus ojos, y es en ese mismo lugar sensible donde llegará la sangre luminosa y ardiente del amaru convocante y liberador.

En esta tembladera del mundo (katatay), se conciertan varios elementos: el taki onqoy, danza posesiva para curar el mundo enfermo; el danzante de tijeras o danzak, para estimular el movimiento de cuerpos colectivos; el Inkarrí que trae el retorno de los tiempos quebrados y reprimidos que empiezan a convocarse y unirse, tiempos viejos que rejuvenecen; el tusuy, la danza para vivir y cambiar, para envolver el mal tiempo y lazarlo con sus movimientos intensos, soltando la mala energía; y yawar o la sangre como fuerza impulsora, como luz y alma del Sol. Además, hay un fuerte componente religioso de los apus (dioses andinos), como el Tata Inti, la Mama Killa, el kundur, el amaru, todos convocados y que convocan para que el pueblo se junte y transforme el mundo, para que la alegría empiece a poblar los múltiples rostros del pueblo indio. En tal sentido, este poema es un enorme canto al pueblo trasformador, al reconocimiento de su voluntad por unirse; pero, a la vez, es un himno a la vida andina y a toda forma de vida limpia que se carga de colores y músicas para avanzar y sentir un allin kawsay, un buen vivir. Para llegar a todo esto, se tiene que operar un pachakutiy. Por ello, la transformación se anuncia siempre como un día resplandeciente, como un día singular donde se produce el pachakutiy, donde todo el mundo danza: los dioses, los cielos, los hombres, la candela, los árboles, todos configurando una libertad festiva.

\section{Agradecimientos}

Esta investigación estuvo auspiciada por el Vicerrectorado de Posgrado e 
Investigación de la Universidad Nacional Mayor de San Marcos y corresponde al proyecto titulado "Representación del Pachakutiy en la poesía quechua peruana contemporánea. José María Arguedas, Kilku Warak’a, César Guardia Mayorga, Eduardo Ninamango Mallqui, Dida Aguirre" (2016). Grupo de Investigación Estudios Andinos de Interculturalidad: quechua-aymara (ESANDINO)

\section{Notas}

1 En la primera edición se incluyeron seis poemas y llevó el título de Katatay y otros poemas. Huc jayllucunapas (1972); luego, en las ediciones posteriores, se sumó el poema "Qollana Vietnam llaqtaman / Ofrenda al pueblo de Vietnam" (traducido por Alfredo Torero y revisado por José María Arguedas) y el título de esta compilación de poemas queda solo con el nombre de Katatay. Actualmente tenemos reunidos 18 poemas.

2 Un primer acercamiento a este intenso poema quechua se encuentra en mi libro José María Arguedas. Urpi, fieru, quri, sonqoyky. Estudio sobre la poesía de Arguedas (Mamani, 2011, pp. 111-125).

\section{Referencias bibliográficas}

Arguedas, J. M. (1984). Katatay. Lima: Horizonte.

Arguedas, J. M. (2007). Dioses y hombres de Huarochirí. Narraciones quechuas recogidas por Francisco de Ávila (traducción de José María Arguedas). Lima: Universidad Antonio Ruiz de Montoya.

Arnold, D. y De Dios Yapita, J. (1992). Sallqa. Dirigirse a las bestias silvestres en los andes meridionales. En D. Arnold, D. Jiménez y J. de Dios Yapita (eds.), Hacia un orden andino de las cosas (pp. 175-212). La Paz: HISBOL, ILCA.

Avendaño, Á. (1988). La rebelión de los mallkis: medicina popular quechua. Lima: Antawara.

Ayala Leonardi, F. de M. (2002). Aportes para un diccionario mitológico andino. Huancayo: Universidad Nacional del Centro del Perú.

Cerrón-Palomino, R. (1994). Quechua sureño. Diccionario unificado. Lima: Biblioteca Nacional del Perú.

Cerrón- Palomino, R. (Ed.). (2014). Arte y vocabulario en la lengua general del 
Perú/ Anónimo [1586]. Lima: Pontificia Universidad Católica del Perú, Instituto Riva-Agüero.

Escobar, A. (1972). Presentación. En José María Arguedas, Katatay y otros poemas. Huc Jayllicunapas (pp. 9-11). Lima: Instituto Nacional de Cultura.

Espino, G. (2012). La poesía de José María Arguedas. CELEHIS. Revista del Centro de Letras Hispanoamericanas, 21, 23, 21-38. Recuperado de: https:// fh.mdp.edu.ar/revistas/index.php/celehis/article/download/106/194

González Holguín, D. (1989 [1952]). Vocabulario de la lengua general de todo el Perú llamada Lengua Qquechua o del inca. Lima: Universidad Nacional Mayor de San Marcos.

Gutmann, M. (1993). Visión andina del mundo y conceptos religiosos en cuentos orales quechuas del Perú. En H. Urbano (Comp.), Mito y simbolismo en los andes. La figura y la palabra (pp. 239-258). Cusco: Centro de Estudios Regionales Andinos Bartolomé de Las Casas.

Huamán, M. Á. (1988). Poesía y utopía andina. Lima: Centro de Estudios y Promoción de Desarrollo-Desco.

Larrú Salazar, M. (2003). La utopía posible en la poesía de Arguedas. Lhymen, 2, 63-71.

Lienhard, M. (1998). Pachacutiy taki: canto y poesía en la transformación del mundo. Oralidad. Lengua, identidad y memoria de América, 9, 30-41. Recuperado de http://www.lacult.unesco.org/docc/oralidad_09_30-41pachakutiy-taki.pdf

Lienhard, M. (2008). Disidentes, rebeldes, insurgentes. Resistencia indígena y negra en América Latina. Ensayo de historia testimonial. Madrid: Iberoamericana, Vervuert.

Limón Olivera, S. (1990). Las cuevas y el mito de origen: los casos inca y mexica. Ciudad de México: Dirección General de Publicaciones.

Lira, J. A. y Mejía Huamán, M. (2008). Diccionario quechua-castellano. Castellano-quechua. Lima: Universidad Ricardo Palma.

López-Baralt, M. (2011). El Inca Garcilaso, traductor de culturas. Madrid: Iberoamerica, Vervuert. 
Mamani Macedo, M. (2011). José María Arguedas. Urpi, fieru, quri, sonqoyky [Tu corazón es de fierro, de oro de paloma]. Lima: Petroperú.

Melgar, A. y Cavero, R. (2007). El Taki Onqoy. Lima: Altazor.

Murra, J. V. (2014). El mundo andino. Población, medio ambiente y economía. Lima: Instituto de Estudios Peruanos, Pontificia Universidad Católica del Perú.

Noriega Bernuy, J. E. (2011). Escritura quechua en el Perú. Lima: Pakarina Editores.

Noriega Bernuy, J. E. (2012). Caminan los apus. Escritura andina en migración. Lima: Pakarina Editores, Knox College.

Rivera Andía, J. J. (2006). Mitología en los andes. En A. Ortiz Rescaniere (Ed.), Mitologías amerindias (pp. 129-176). Madrid: Trotta. 